\title{
The Effect of Healthcare Provider Availability on Spine Spending
}

\author{
Benjamin A. Y. Cher, M.S. ${ }^{7}$ (1), Olga Yakusheva, Ph.D. ${ }^{2,3}$, Haiyin Liu, M.A. ${ }^{3}$, \\ Julie P. W. Bynum, M.D., M.P.H. ${ }^{4}$, and Matthew A. Davis, M.P.H., Ph.D.,
}

'University of Michigan Medical School, Ann Arbor, MI, USA; ${ }^{2}$ Department of Health Management and Policy, University of Michigan School of Public Health, Ann Arbor, MI, USA; ${ }^{3}$ Department of Systems, Populations, and Leadership, University of Michigan School of Nursing, Ann Arbor, MI, USA; ${ }^{4}$ Department of Internal Medicine, Geriatric and Palliative Medicine, University of Michigan Medical School, Ann Arbor, MI, USA; ${ }^{5}$ Department of Learning Health Sciences, University of Michigan Medical School, Ann Arbor, MI, USA.

BACKGROUND: Spine conditions are costly and a major cause of disability. A growing body of evidence suggests that healthcare utilization and spending are driven by provider availability, which varies geographically and is a topic of healthcare policy debate.

OBJECTIVE: To estimate the effect of provider availability on spine spending.

DESIGN: Retrospective cohort study using relocation as a natural experiment.

PARTICIPANTS: Fee-for-service Medicare beneficiaries over age 65 who relocated to a new hospital referral region between 2010 and 2014.

MAIN MEASURES: We used generalized linear models to evaluate how changes in per-beneficiary availability of three types of healthcare providers (primary care physicians, spine surgeons, and chiropractors) affected annual perbeneficiary spine spending. We evaluated increases and decreases in provider availability separately. To account for the relative sizes of the provider workforces, we also calculated estimates of the effects of changes in national workforce size on changes in national spine spending.

KEY RESULTS: The association between provider availability and spending was generally stronger among beneficiaries who experienced a decrease (versus an increase) in availability. Of the three provider groups, spine surgeon availability was most strongly associated with spending. Among beneficiaries who experienced a decrease in availability, a decrease in one spine surgeon per 10,000 beneficiaries was associated with a decrease of \$36.97 (95\% CI: \$12.51, \$61.42) in annual spending per beneficiary, versus a decrease of $\$ 1.41$ (95\% CI: \$0.73, \$2.09) for a decrease in primary care physician availability. However, changes in the national workforce size of primary care physicians were associated with the largest changes in national spine spending.

CONCLUSIONS: Provider availability affects individual spine spending, with substantial changes observed at the national level. The effect depends on provider type and whether availability increases or decreases. Policymakers should consider how changes in the size of the physician workforce affect healthcare spending.

Electronic supplementary material The online version of this article (https://doi.org/10.1007/s11606-020-06191-5) contains supplementary material, which is available to authorized users.

Received March 31, 2020

Accepted August 27, 2020

Published online September 15, 2020
KEY WORDS: provider availability; physician workforce; healthcare spending; back pain.

$\mathrm{J}$ Gen Intern Med 36(3):654-61

DOI: $10.1007 / \mathrm{s} 11606-020-06191-5$

(c) Society of General Internal Medicine 2020

\section{INTRODUCTION}

Spine conditions are exceedingly common, among the top causes of disability, and associated with costs upwards of $\$ 86$ billion per year to the US economy. ${ }^{1-5}$ In the absence of red flag signs and symptoms, clinical management of spine conditions such as back and neck pain is often discretionary, and established practice guidelines recommending conservative management are often overlooked. ${ }^{6}$ Several studies have documented substantial geographical variation in the use of costly services including diagnostic imaging and spine surgery, suggesting differences in management across the USA ${ }^{7-}$ ${ }^{12}$ Efforts to develop cost-effective strategies for managing spine conditions at the population level require a thorough understanding of what drives utilization and costs.

Studies dating back to the 1990s have found availability of healthcare providers to be associated with utilization and spending ("supplier-induced demand"). ${ }^{13-16}$ For spine conditions, variation in surgery rates has been a focus of prior investigation. However, studies that have examined spine surgery rates in relation to availability of healthcare providers have produced conflicting results. While some find an association between the number of spine surgeons and regional surgical rates, ${ }^{9,} 17$ others find little to no relationship. ${ }^{7}$ It is unclear whether these inconsistent findings are due to methodologic shortcomings of their observational study designs or other inherent differences. Additionally, prior studies have only examined the availability of spine surgeons. However, a variety of healthcare providers other than surgeons (e.g., primary care physicians and ancillary providers such as chiropractors) manage spine conditions, and each may influence spine spending differently. ${ }^{18,19}$ Lastly, prior studies have 
examined the relationship between healthcare availability surgical rates, but none has examined spine spending directly.

Therefore, we examined the relationship between geographic per-capita availability of three types of providers who treat spine conditions (primary care physicians, spine surgeons, and chiropractors) and spine spending using a novel study design better able to estimate causal relationships than prior work. We used a natural experiment consisting of a large cohort of Medicare beneficiaries who relocated geographically and experienced a change in provider availability. This allowed us to examine changes in spine spending (before versus after relocation) in response to changes in availability of providers.

\section{METHODS}

Among a large cohort of older adults, we used a natural experiment to examine the relationship between the availability of healthcare providers who commonly manage spine conditions and spine spending. We leveraged data from Medicare beneficiaries who relocated once during a 5-year time span and experienced a change in provider availability. We then examined the effect of this change in provider availability on spine spending. The benefit of this design based on migration is that it examines the within-person effect of change in provider availability, where confounding by unobserved variables is mitigated because each patient serves as his/her own control. $^{20,21}$ By comparing spending among beneficiaries who experienced different changes in provider availability, we mitigate confounding based on factors associated with beneficiaries' decisions to move.

Our study of administrative claims and publicly available data received an expedited approval by the University of Michigan Health and Behavioral Sciences Institutional Review Board.

\section{Study Population}

We identified 16,842,729 beneficiaries aged 65 and older who were enrolled in Medicare parts A and B during the 5-year time period between 2010 and 2014 (Fig. 1). For each of the 5 years, residential ZIP codes were merged to the 306 hospital referral regions (HRRs) that represent regional healthcare markets. $^{22}$ We identified 887,917 beneficiaries who moved once, defined as changing to a different HRR. After restricting to beneficiaries whose records included at least 2 years of complete data before and after relocation, our final sample size was 405,325 Medicare beneficiaries.

\section{Provider Availability}

Our primary independent variable was provider availability at the HRR level per 10,000 Medicare beneficiaries. We focused on US providers who commonly manage spine conditions. We examined availability of primary care physicians (internal

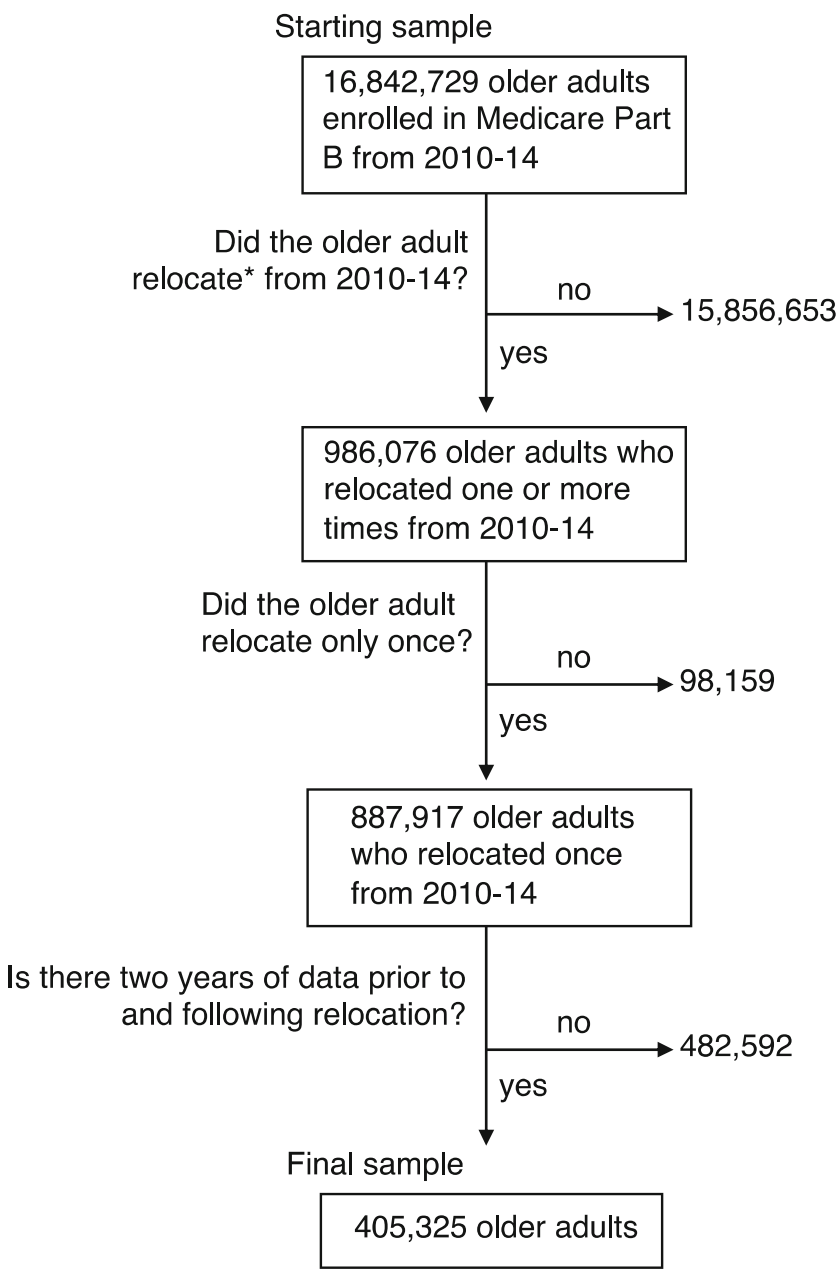

Figure 1 Flow diagram of study inclusion. Relocation (indicated by the asterisk symbol) defined as changing between hospital referral regions based on the residential address in the Master Beneficiary Summary File.

medicine, family practice, and general practice) because low back pain is one of the most common reasons adults visit primary care physicians. ${ }^{23}$ We examined availability of spine surgeons because spine conditions are often managed surgically. We examined chiropractors as an example of a provider that operates outside the conventional medical system.

We used data from the National Plan and Provider Enumeration System (NPPES) for 2012 (the midpoint of the time period) to identify relevant healthcare providers. Provider specialty codes 11 (internal medicine), 08 (family practice), and 01 (general practice) were used to identify primary care physicians. $^{24}$ Provider specialty codes 20 (orthopedic surgeons) and 14 (neurosurgeons) were used to identify spine surgeons. ${ }^{24}$ Provider specialty code 35 was used to identify chiropractors. $^{24}$ Providers who were not treating Medicare beneficiaries were removed by identifying those not submitting claims in the $20 \%$ Carrier file. As there are many orthopedic surgeons and neurosurgeons who do not perform spine surgery, we removed spine surgeons who did not have evidence of at least one claim for spine surgery during the calendar year based on Healthcare Common Procedure 
Coding System (HCPCS) codes. After applying exclusion criteria, we identified 260,572 primary care physicians, 21,020 spine surgeons, and 45,264 chiropractors.

\section{Spine Spending}

The primary dependent variable was inflation-adjusted annual spine spending per beneficiary, measured before and after relocation. We calculated the change in spending per beneficiary associated with relocation, defined as the difference between the average annual spending over the two calendar years before and the two calendar years after the relocation year. Because there was no way to identify the exact month in which the beneficiary relocated, we discarded data from the year in which beneficiaries moved and used data from years before and after the year of relocation. We used the combination of ResDAC's Carrier, MEDPAR, and Outpatient files to calculate total spending on spine conditions. A list of established diagnosis codes was used to identify spine diagnoses. ${ }^{4}$ A claim was defined as spine-related if any of these diagnosis codes appeared on the claim.

We calculated spine spending on inpatient and ambulatory care separately. For ambulatory care, we used BerensonEggers Type of Service to identify spending on "evaluation and management," "medical procedures," and "imaging and testing." Of note, for inpatient spending, we were unable to separate spending on evaluation, management, procedures, and imaging with available data.

All spending was adjusted for inflation to 2014 dollars using the Consumer Price Index for medical services. ${ }^{25}$

\section{Covariates}

We collected data on sociodemographic characteristics such as age, sex, and race/ethnicity from the Master Beneficiary Summary File. To account for differences in health status and potential changes in health status over time, we calculated the Charlson-Deyo Comorbidity Index ${ }^{26}$ for each calendar year. For each ZCTA, both at baseline and post-relocation, we used Rural-Urban Community Area Codes to identify it as being either rural or urban. ${ }^{17}$ We also collected median household income at the US county level to account for differences in regional socioeconomic status before versus after relocation. ${ }^{4}$

\section{Statistical Analysis}

For each provider type, we used generalized linear models to estimate the change in spending as a function of the change in provider availability. The change in provider availability was interacted with an indicator variable of whether a beneficiary experienced an increase or a decrease in provider availability, allowing us to separately examine the effects of introducing and removing providers from the healthcare system. For each spending endpoint (total, inpatient, ambulatory, evaluation and management, medical procedures, and imaging/testing), each model was controlled for the covariates described above.
In addition, we controlled for pre-relocation provider availability and total spending, to account for baseline differences in healthcare utilization between beneficiaries and focus our analysis on the changes experienced by beneficiaries in relation to their move. We also accounted for secular trends by controlling for relocation year. Since availability of chiropractors is correlated with availability of primary care physicians, ${ }^{27}$ we adjusted models of chiropractor availability for primary care physician availability.

Since the number of primary care physicians greatly exceeds the number of spine surgeons, we estimated the relationship between provider availability and spine spending at the national scale, by extrapolating our estimates to represent the 47.8 million older adults in the USA. ${ }^{28}$ Adjusted point estimates generated from our models were scaled relative to the number of providers. We examined the relationships between $1 \%, 5 \%, 10 \%$, and $20 \%$ changes in provider availability and national spending.

We also conducted a sub-analysis restricted to beneficiaries who had any spine spending prior to relocation.

Analyses were based on complete case analysis, and any missing data were assumed to be missing completely at random. A two-sided $p$ value of 0.05 was considered statistically significant. Analyses were conducted using SAS version 9.4 (Cary, NC) and Stata version 15.0 (College Station, TX).

\section{RESULTS}

Among the 405,325 older adults in our study population, $60.0 \%$ were female and $89.8 \%$ were white (Table 1). At baseline (i.e., in the 2 years prior to relocation), the most common comorbidities were diabetes $(21.5 \%)$ and chronic obstructive pulmonary disease $(14.0 \%)$. The mean comorbidity score was 0.7 , with 237,325 beneficiaries $(68.6 \%)$ having

Table 1 Characteristics of the Study Population

\begin{tabular}{ll}
\hline \hline Total sample (no.) & 405,325 \\
Sociodemographic characteristics & $76.2(7.5)$ \\
Mean age in years (SD) & $243,392(60.0)$ \\
Female sex, no. (\%) & \\
Race, no. (\%) & $363,830(89.8)$ \\
White & $22,350(5.5)$ \\
Black & $19,145(4.7)$ \\
Other & \\
Health status & $0.7(0.9)$ \\
Mean comorbidity score (SD) & \\
Comorbidities, no. (\%) & $86,937(21.5)$ \\
Diabetes without chronic complication & $56,681(14.0)$ \\
Chronic obstructive pulmonary disease & $40,713(10.0)$ \\
Cerebrovascular disease & $32,009(7.9)$ \\
Congestive heart failure & $31,975(7.9)$ \\
Renal disease & \\
Healthcare availability and spending & \\
Mean provider availability per 10,000 capita (SD) & $99(36)$ \\
Primary care physicians & $2(1)$ \\
Spine surgeons & $17(8)$ \\
Chiropractors & $738.3(3421.3)$ \\
Mean annual spine spending, 2014 dollars (SD) & $419.3(2849.0)$ \\
Inpatient & $319.0(1110.8)$ \\
Ambulatory & $56.2(159.6)$ \\
Evaluation and management & $90.5(460.3)$ \\
Medical procedures & $42.1(137.8)$ \\
$\quad$ Imaging and testing & \\
\hline
\end{tabular}


at least one comorbidity. Inpatient spending accounted for $56.8 \%$ of all spine spending. Of ambulatory spending, medical procedures accounted for $28.4 \%$ of spending, a greater proportion than accounted for by evaluation and management (17.6\%) and imaging and testing (13.2\%). Across HRRs, the mean availability was 99 (range 38 to 364) primary care physicians per 10,000 beneficiaries, 2 (range 0 to 4 ) spine surgeons per 10,000 beneficiaries, and 17 (range 3 to 68) chiropractors per 10,000 beneficiaries.

\section{Effect of Healthcare Provider Availability on Spine Spending}

Overall, the association between healthcare provider availability and annual spine spending was greater among those who experienced a decrease in availability after relocation versus those who experienced an increase in availability (Fig. 2). Among those who experienced a decrease in availability, a reduction of one spine surgeon per 10,000 beneficiaries was associated with a decrease of $\$ 36.97$ (95\% confidence interval [CI]: $\$ 12.51$, $\$ 61.42$ ) in annual spine spending per beneficiary. A reduction of one primary care physician per 10,000 beneficiaries was associated with a decrease of $\$ 1.41$ (95\% CI: $\$ 0.73, \$ 2.09)$ in annual spine spending per beneficiary. For chiropractors, the association was not statistically significant; a reduction of one chiropractor per 10,000 beneficiaries was associated with a decrease of $\$ 1.47$ (95\% CI: $\$-1.63, \$ 4.56)$ in annual spine spending per beneficiary. Among older adults who experienced an increase in provider availability, associations were attenuated - the only statistically significant association was for primary care physician availability and spine spending.

Differences in spine spending were driven primarily by inpatient spending (Table 2). For instance, among older adults who experienced a decrease in primary care physician availability, average inpatient spending decreased by $\$ 1.28$ (95\% CI: 0.65 , 1.90 ) with a decrease in one primary care physician per 10,000 beneficiaries, versus a decrease of $\$ 1.41$ (95\% CI: 0.73, 2.09) for total spine spending. Likewise, average inpatient spending decreased by $\$ 35.75$ (95\% CI: $13.38,58.11)$ with a decrease in availability of spine surgeons. There was no statistically significant change in ambulatory spending for these provider groups.

Changes in spine spending at the population level were largely driven by patients with any spine spending prior to relocation (Appendix, Figure 4).

\section{National Estimates}

Accounting for the relative sizes of the different provider groups and extrapolating to the US population of older adults, changes in the national workforce size of primary care physicians would lead to the greatest changes in national spine spending (Fig. 3). For instance, a reduction of the primary care workforce by $5 \%$ would be associated with a $\$ 333.8$ (95\% CI: \$172.8, \$495.0) million decrease in national spine spending per year. Considering expansions of the primary care workforce, increases of $1 \%$ and $20 \%$ would be associated with

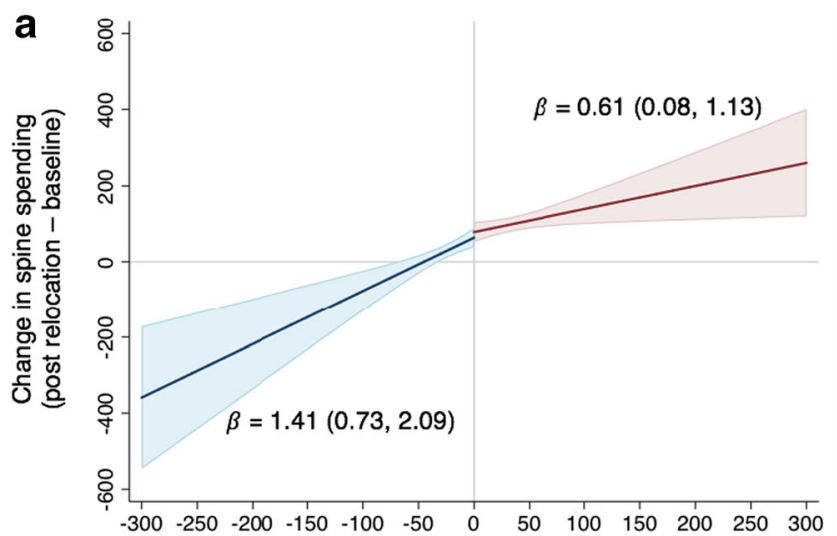

b



C

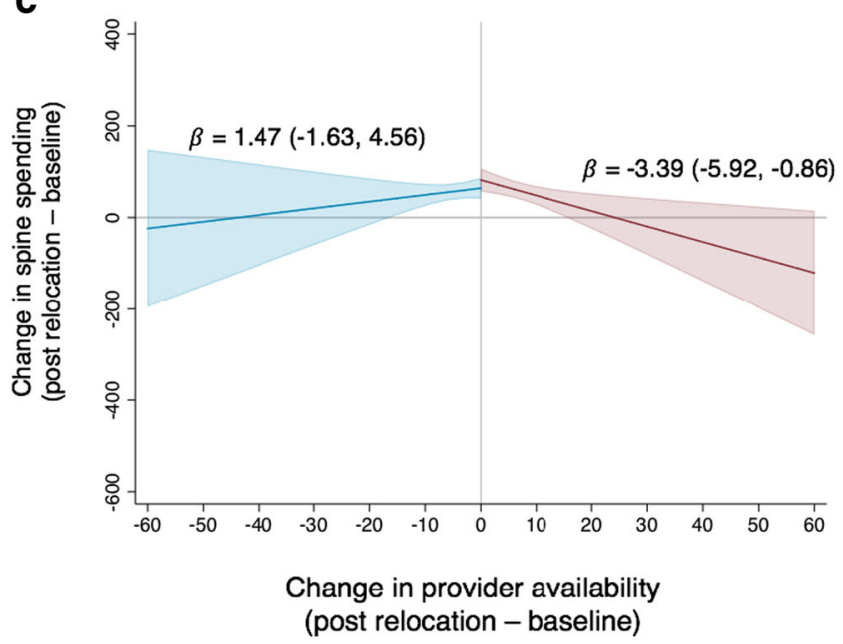

Figure 2 Effect of changes in availability of primary care physicians (a), spine surgeons (b), and chiropractors (c) on change in spine spending (post relocation minus baseline). All analyses adjusted for beneficiary characteristics (age, sex, race, clinical comorbidities), rurality, and regional median household income.

increases of $\$ 28.8$ (95\% CI: $\$ 4.0, \$ 53.6$ ) million and $\$ 575.5$ (95\% CI: \$79.4, \$1071) million, respectively.

\section{DISCUSSION}

Our study used a natural experiment to evaluate the relationship between availability of providers that manage spine conditions and spine spending. We found that Medicare 
Table 2 Effect of Changes in Availability of Primary Care Physicians, Spine Surgeons, and Chiropractors on Change in Spine Spending (Post Relocation Minus Baseline), by Spending Type

\begin{tabular}{|c|c|c|}
\hline & \multicolumn{2}{|c|}{$\begin{array}{l}\text { Mean spending difference per beneficiary with a change of } 1 \text { provider per } 10,000 \\
\text { beneficiaries, } 2014 \text { dollars }(95 \% \mathrm{CI})\end{array}$} \\
\hline & $\begin{array}{l}\text { Among those who experienced } \\
\text { a decrease in provider availability }\end{array}$ & $\begin{array}{l}\text { Among those who experienced } \\
\text { an increase in provider availability }\end{array}$ \\
\hline \multicolumn{3}{|l|}{ Primary care physicians } \\
\hline Total spine spending & $-1.41(-2.09,-0.73)$ & $0.61(0.08,1.13)$ \\
\hline \multicolumn{3}{|l|}{ By type } \\
\hline Inpatient & $-1.28(-1.90,-0.65)$ & $0.87(0.39,1.35)$ \\
\hline Ambulatory & $-0.13(-0.37,0.11)$ & $-0.27(-0.45,-0.08)$ \\
\hline Evaluation and management & $0.01(-0.02,0.05)$ & $-0.01(-0.04,0.01)$ \\
\hline Medical procedures & $0.03(-0.08,0.13)$ & $-0.11(-0.19,-0.03)$ \\
\hline Imaging and testing & $0.01(-0.02,0.04)$ & $-0.06(-0.09,-0.04)$ \\
\hline \multicolumn{3}{|l|}{ Spine surgeons } \\
\hline Total spine spending & $-36.97(-61.42,-12.51)$ & $15.51(-32.41,63.42)$ \\
\hline \multicolumn{3}{|l|}{ By type } \\
\hline Inpatient & $-35.75(-58.11,-13.38)$ & $20.34(-23.49,64.16)$ \\
\hline Ambulatory & $-1.22(-9.81,7.36)$ & $-4.83(-21.65,11.99)$ \\
\hline Evaluation and management & $1.57(0.29,2.84)$ & $-1.03(-3.54,1.47)$ \\
\hline Medical procedures & $2.01(-1.69,5.72)$ & $-0.17(-7.43,7.09)$ \\
\hline Imaging and testing & $0.56(-0.57,1.69)$ & $-2.97(-5.18,-0.76)$ \\
\hline \multicolumn{3}{|l|}{ Chiropractors } \\
\hline Total spine spending & $-1.47(-4.56,1.63)$ & $-3.39(-5.92,-0.86)$ \\
\hline \multicolumn{3}{|l|}{ By type } \\
\hline Inpatient & $-0.94(-3.77,1.89)$ & $-2.74(-5.05,-0.43)$ \\
\hline Ambulatory & $-0.53(-1.62,0.56)$ & $-0.65(-1.53,0.24)$ \\
\hline Evaluation and management & $-0.03(-0.19,0.13)$ & $-0.19(-0.33,-0.06)$ \\
\hline Medical procedures & $-0.21(-0.68,0.26)$ & $-0.18(-0.57,0.20)$ \\
\hline Imaging and testing & $0.16(0.02,0.30)$ & $-0.17(-0.28,-0.05)$ \\
\hline
\end{tabular}

All analyses adjusted for beneficiary characteristics (age, sex, race, clinical comorbidities), rurality, and regional median household income

beneficiaries who experienced a decrease in availability had greater changes in spending compared with those who experienced an increase in availability. Additionally, we found that availability of spine surgeons (versus primary care physicians and chiropractors) was most strongly associated with spine spending. However, when we extrapolated our estimates to the entire older adult population and accounted for differences in workforce size by provider type, we found that changes in the primary care workforce would have the largest effect on national spine spending. For instance, we estimate that a 5\% reduction in the primary care physician workforce would decrease national spine spending by $\$ 333$ million, versus a $\$ 176$ million reduction in spending for a 5\% decrease in spine surgeons.

In the context of prior work, our results support findings of a positive association between spine surgeon availability and surgery rates. ${ }^{9,}{ }^{17}$ We offer a higher level of causal inference suggesting provider availability might explain observed geographic variation observed in spine care. ${ }^{7-10,13-16}$ Our results also align with findings of supply-sensitive care in other fields such as emergency medicine and pediatrics. ${ }^{29,} 30$

Policymakers designing strategies to improve access to healthcare resources should be aware of how changes in provider availability might affect healthcare spending. For example, our observation of stronger effects on spending among those who experienced a reduction (versus an increase) in healthcare availability suggests the removal of services has a stronger effect on spending, at least in the short term. It is conceivable that more time may be required for spending to change as older adults become accustomed to using newly available services. In addition, for health issues such as spine conditions that are treated by several different types of providers, our findings demonstrate the importance of understanding how provider types affect spending differently. A possible explanation of our findings is that in areas of high provider availability, there are differences in practice load by provider type. In high availability areas, surgeons may be busier, and less able to increase capacity, than primary care physicians. This could explain why we did not observe increased spine spending with increased availability of spine surgeons. Lastly, the spending changes we observed, together with prior work demonstrating variation in spine surgery rates ${ }^{7-12}$ speak to the discretionary nature of spine care. Studies of variation in healthcare often find that high costs are not associated with better outcomes. ${ }^{31,32}$ Further research is required to understand whether this holds true for spine conditions. Nevertheless, since factors such as geographic location and provider availability impact spine spending, there may be opportunities for improvement in the clinical management of spine conditions.

The American Association of Medical Colleges predicts that the USA will face a shortage of 21,100 to 55,200 physicians by 2032 , with primary care physicians expected to account for about half of the shortage. ${ }^{28}$ Although the shortage is controversial for several reasons (e.g., issues regarding the distribution of physicians between urban and rural areas ${ }^{33,34}$ ), many advocate for policy changes including training more physicians ${ }^{35}$ and non-physician clinicians. ${ }^{36}$ Most advocate 


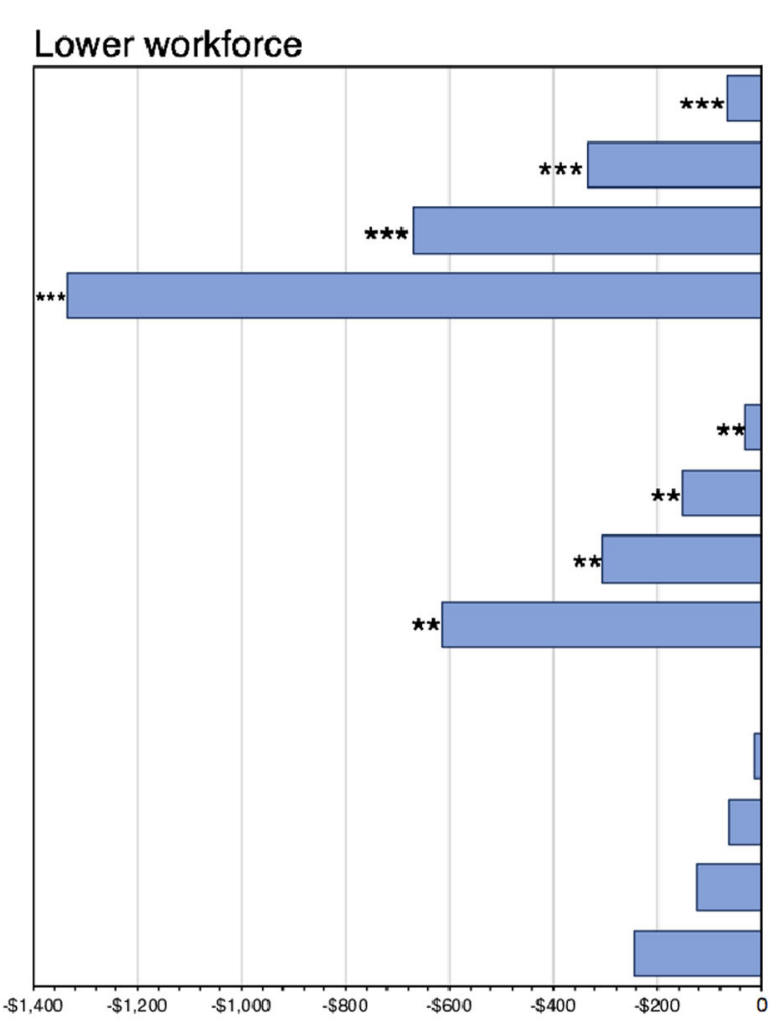

Estimated national spending, millions

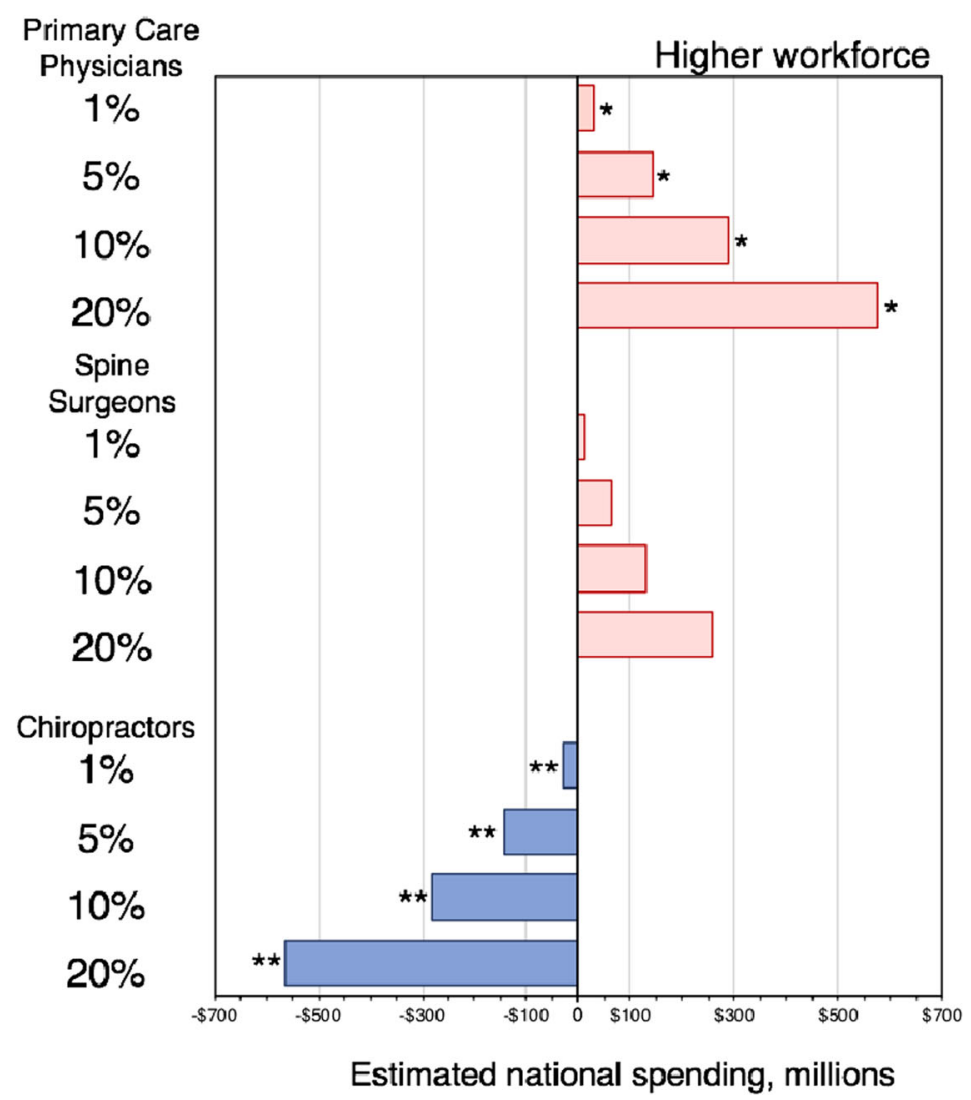

Figure 3 Estimated change national spine spending based on $1 \%, 5 \%, 10 \%$, and $20 \%$ changes in provider workforce sizes of primary care physicians, spine surgeons, and chiropractors. All analyses adjusted for beneficiary characteristics (age, sex, race, clinical comorbidities), rurality, and regional median household income. $*$ value $<0.05 ; * * p$ value $<0.01 ; * * p$ value $<0.001$.

for expansion of the US workforce of primary care physicians. We estimate that changes in the size of the primary care workforce, given its large size, would lead to substantial increases in spine spending. However, the manner in which the size of the primary care workforce affects spine spending is not entirely intuitive. Interestingly, we found that changes in spine spending associated with changes in the availability of primary care physicians were driven mainly by inpatient spending. Also, we observed decreases in spending on outpatient services such as diagnostic imaging and procedures with increases in primary care physician availability. A possible explanation is that primary care physicians are a portal of entry to the healthcare system, providing referrals to specialists who rely more on more costly inpatient diagnostic imaging, procedures, and treatment. Additionally, our finding that ambulatory imaging increased as surgeon availability decreased suggests the behavior of primary care physicians may be affected by the availability of other providers, especially in regions with lower availability of spine surgeons. Our findings speak to the inter-connectedness of inpatient and outpatient medicine - studies of healthcare supply and demand must consider both inpatient and outpatient factors on both the supply side and the demand side.

There are several limitations to our study that must be acknowledged. First, the study population consisted of older
Medicare beneficiaries enrolled in part B who relocated, so the results may not be generalizable to the entire population of patients with spine conditions. However, there is no evidence that estimates among movers and non-movers would differ any meaningful ways. Second, our study was limited to detecting changes in spending 2 years after relocation. It is possible the changes in spending we observed would be different over a longer time period, particularly for beneficiaries who moved to areas of higher provider availability and therefore were not required to make immediate behavior changes. Third, despite the rigorous design of our study, we cannot completely rule out the possibility of residual confounding. Residual confounding among beneficiaries is unlikely since each study participant served as his/her own control. However, there may be additional differences between hospital referral regions, such as hospital access, that are associated with provider availability and/or spending. We consider provider availability a surrogate measure of general healthcare availability. Fourth, since our analyses used entirely administrative claims, we were not able to determine "high value" versus "low value" spine spending, i.e., whether differences in spending were associated with differences in functional outcomes. Future work should investigate the effect of a decrease in provider availability on spine care outcomes, as has been done in several other health conditions. ${ }^{37,38}$ 
This study offers several important contributions. To our knowledge, this study is the first to use a natural experiment based on patient relocation to evaluate the relationship between provider availability and spending. We provide healthcare policymakers with estimates about how changes in the size of the healthcare workforce will affect spine spending. We also suggest that policymakers must be mindful that different provider types affect spending differently, and that the healthcare system reacts differently to increases versus decreases in resource availability. Our findings can aid policymakers in evaluating a possible physician shortage, considering interventions to change the supply of physicians, and answering broader questions about the effect of the supply of healthcare resources on utilization.

Corresponding Author: Benjamin A. Y. Cher, M.S.; University of Michigan Medical School, Ann Arbor, MI, USA (e-mail: bcher@umich. edu).

Funding This work was supported by Award Number 1R01AT009003 from the National Center for Complementary \& Integrative Medicine at the National Institutes of Health.

\section{Compliance with Ethical Standards:}

Our study of administrative claims and publicly available data received an expedited approval by the University of Michigan Health and Behavioral Sciences Institutional Review Board.

Conflict of Interest: $M A D$ receives consulting fees from the American Society of Regional Anesthesia and Pain Medicine, a non-profit organization, for statistical review of manuscripts for the society's scientific journal. These fees are unrelated to the current manuscript. The remaining authors have nothing to disclose.

Disclaimer: The views expressed herein do not necessarily represent the official views of the National Center for Complementary \& Integrative Medicine or the National Institutes of Health

\section{REFERENCES}

1. Murray CJ, Atkinson C, Bhalla K, et al. The state of US health, 19902010: burden of diseases, injuries, and risk factors. Jama. 2013;310(6):591-608.

2. Docking RE, Fleming J, Brayne C, Zhao J, Macfarlane GJ, Jones GT. Epidemiology of back pain in older adults: prevalence and risk factors for back pain onset. Rheumatology (Oxford). 2011;50(9): 1645-1653.

3. Davis MA, Onega T, Weeks WB, Lurie JD. Where the United States spends its spine dollars: expenditures on different ambulatory services for the management of back and neck conditions. Spine. 2012;37(19):1693-1701

4. Martin BI, Deyo RA, Mirza SK, et al. Expenditures and health status among adults with back and neck problems. Jama. 2008;299(6):656664.

5. Martin BI, Turner JA, Mirza SK, Lee MJ, Comstock BA, Deyo RA. Trends in health care expenditures, utilization, and health status among US adults with spine problems, 1997-2006. Spine. 2009;34(19):20772084

6. Mafi JN, McCarthy EP, Davis RB, Landon BE. Worsening trends in the management and treatment of back pain. JAMA Intern Med. 2013:173(17):1573-1581.
7. Weinstein JN, Lurie JD, Olson PR, Bronner KK, Fisher ES. United States' trends and regional variations in lumbar spine surgery: 19922003. Spine. 2006;31(23):2707-2714.

8. Lurie JD, Birkmeyer NJ, Weinstein JN. Rates of advanced spinal imaging and spine surgery. Spine. 2003;28(6):616-620.

9. Lurie JD, Weinstein JN. Shared decision-making and the orthopaedic workforce. Clin Orthop Relat Res. 2001(385):68-75.

10. Volinn E, Mayer J, Diehr P, Van Koevering D, Connell FA, Loeser JD. Small area analysis of surgery for low-back pain. Spine. 1992;17(5):575581.

11. Cram P, Landon BE, Matelski J, et al. Utilization and Outcomes for Spine Surgery in the United States and Canada. Spine. 2019;44(19):1371-1380.

12. Liu CY, Zygourakis CC, Yoon S, et al. Trends in Utilization and Cost of Cervical Spine Surgery Using the National Inpatient Sample Database, 2001 to 2013. Spine. 2017;42(15):E906-e913.

13. Fisher ES, Wennberg JE. Health care quality, geographic variations, and the challenge of supply-sensitive care. Perspect Biol Med. 2003;46(1):6979.

14. Rohrer JE. Supply-induced demand for hospital care. Health services management research. 1990;3(1):41-48.

15. Wennberg JE. Unwarranted variations in healthcare delivery: implications for academic medical centres. BMJ (Clinical research ed). 2002;325(7370):961-964.

16. Ricketts TC, Belsky DW. Medicare costs and surgeon supply in hospital service areas. Ann Surg. 2012;255(3):474-477.

17. Cherkin DC, Deyo RA, Loeser JD, Bush T, Waddell G. An international comparison of back surgery rates. Spine. 1994;19(11):1201-1206.

18. Fritz JM, Kim J, Dorius J. Importance of the type of provider seen to begin health care for a new episode low back pain: associations with future utilization and costs. J Eval Clin Pract. 2016;22(2):247-252.

19. Horn ME, George SZ, Fritz JM. Influence of Initial Provider on Health Care Utilization in Patients Seeking Care for Neck Pain. Mayo Clin Proc Innov Qual Outcomes. 2017;1(3):226-233.

20. Song Y, Skinner J, Bynum J, Sutherland J, Wennberg JE, Fisher ES. Regional variations in diagnostic practices. N Engl J Med. 2010;363(1):45-53.

21. Molitor D. The Evolution of Physician Practice Styles: Evidence from Cardiologist Migration. Am Econ J Econ Policy. 2018;10(1):326-356.

22. Wennberg JE. The Dartmouth Atlas of health care in the United States (incl. Diskette). American Hospital Association; 1996.

23. Hart LG, Deyo RA, Cherkin DC. Physician office visits for low back pain. Frequency, clinical evaluation, and treatment patterns from a U.S. national survey. Spine. 1995;20(1):11-19.

24. Deyo RA, Weinstein JN. Low back pain. N Engl J Med. 2001;344(5):363370.

25. United States Department of Labor, Bureau of Labor Statistics. Consumer Price Index. 2018; https://www.bls.gov/cpi/. Accessed Feb 15, 2018.

26. Deyo RA, Cherkin DC, Ciol MA. Adapting a clinical comorbidity index for use with ICD-9-CM administrative databases. J Clin Epidemiol. 1992;45(6):613-619.

27. Davis MA, Yakusheva O, Gottlieb DJ, Bynum JP. Regional Supply of Chiropractic Care and Visits to Primary Care Physicians for Back and Neck Pain. J Am Board Fam Med 2015;28(4):481-490.

28. The Complexities of Physician Supply and Demand: Projections from 2017 to 2032. American Association of Medical Colleges. April 2019.

29. Harrison WN, Wasserman JR, Goodman DC. Regional Variation in Neonatal Intensive Care Admissions and the Relationship to Bed Supply. J Pediatr. 2018; 192:73-79 e74.

30. Carter MW, Datti B, Winters JM. ED visits by older adults for ambulatory care-sensitive and supply-sensitive conditions. Am J Emerg Med. 2006;24(4):428-434.

31. Fisher ES, Wennberg DE, Stukel TA, Gottlieb DJ, Lucas FL, Pinder EL. The implications of regional variations in Medicare spending. Part 1: the content, quality, and accessibility of care. Annals of internal medicine. 2003;138(4):273-287.

32. Hussey PS, Wertheimer S, Mehrotra A. The association between health care quality and cost: a systematic review. Annals of internal medicine. 2013;158(1):27-34

33. Gudbranson E, Glickman A, Emanuel EJ. Reassessing the Data on Whether a Physician Shortage Exists. Jama. 2017;317(19):19451946. 
34. Naylor KB, Tootoo J, Yakusheva O, Shipman SA, Bynum JPW, Davis MA. Geographic variation in spatial accessibility of U.S. healthcare providers. PLoS One. 2019;14(4):e0215016.

35. Kirch DG, Petelle K. Addressing the Physician Shortage: The Peril of Ignoring Demography. Jama. 2017;317(19):1947-1948.

36. Bodenheimer TS, Smith MD. Primary care: proposed solutions to the physician shortage without training more physicians. Health Aff (Millwood). 2013;32(11):1881-1886.
37. Kiran T, Glazier RH, Campitelli MA, Calzavara A, Stukel TA. Relation between primary care physician supply and diabetes care and outcomes: a cross-sectional study. CMAJ Open. 2016;4(1):E80-87.

38. Basu S, Berkowitz SA, Phillips RL, Bitton A, Landon BE, Phillips RS. Association of Primary Care Physician Supply With Population Mortality in the United States, 2005-2015. JAMA Intern Med. 2019.

Publisher's Note Springer Nature remains neutral with regard to jurisdictional claims in published maps and institutional affiliations. 